\title{
The multifactorial approach: the psychotic patients Athanassia Kakouri
}

\author{
Address: Open Psychotherapy Centre, Athens, Greece \\ from International Society on Brain and Behaviour: 3rd International Congress on Brain and Behaviour \\ Thessaloniki, Greece. 28 November - 2 December 2007 \\ Published: 17 April 2008 \\ Annals of General Psychiatry 2008, 7(Suppl I):S5 doi:I0.II86/1744-859X-7-SI-S5
}

This abstract is available from: http://www.annals-general-psychiatry.com/content/7/SI/S5

(c) 2008 Kakouri; licensee BioMed Central Ltd.

We present some data from the treatment of psychotic patients through a multifactorial approach which has been developed during 25 years of experience, at the Open Psychotherapy Centre (O.P.C.), an open daily nonresidential therapeutic community environment. The therapeutic approach of the O.P.C. is, mainly, Group Analytic, in combination with Therapeutic Community, Psychodrama and Family Therapy principles. This multifactorial scheme facilitates on the one hand the therapist's role, by the creation of a therapist's group which gets envolved in the whole therapeutic process, while on the other hand it functions more effectively as it engages the psychotic patient as well as his/her family in a wide group therapeutic context, directly or indirectly.

The above data are presented in comparison to the recent relevant literature in an attempt to delineate the interelation of individual and group factors that contribute to the favourable outcome. 